\title{
Designing aspects of bridges placed in active seismic areas
}

\author{
V. Herak Marović, P. Marović \& Ž. Nikolić \\ Faculty of Civil Engineering and Architecture, \\ University of Split, Croatia
}

\begin{abstract}
The national territory of the Republic of Croatia is in a very active seismic area, so earthquake influence on bridge structure is often relevant for the choice of span number, the type of bridge superstructure, piers disposition and their height and stiffness, the connection between piers and superstructure or piers and foundations, dimensioning of elements and reinforcement, detail solutions, material consumption, etc. Mechanical resistance and overall bridge stability must be provided by appropriate design aspects taking care of maximal function, economics and aesthetic performances. The results of the bridge seismic analysis according to the new Eurocode 8/2 code are greater seismic forces and higher seismic capacity of the structure compared to the results of the previous codes. Seismic isolation with elastomeric bearings, placed between bridge superstructure and bridge substructure, is used as a common way to reduce the seismic action to the structure and to prevent structural damage. The response of the seismically isolated bridges is in many cases more complicated than the response of the conventionally designed structures because some parameters which are usually neglected in the analysis of the traditionally designed structures should be taken into account. This paper presents comparative analysis of the results obtained by two different methods proposed in Eurocode 8/2, i.e. the fundamental mode method and the response spectrum method for several seismic isolated viaducts at the Adriatic highway.

Keywords: viaduct, seismic area, isolated bridge, elastomeric bearings, fundamental mode method, response spectrum method.
\end{abstract}




\section{Introduction}

Structural conception of bridges is probably more strictly related to function, aesthetics and economics than in any other type of structures. Therefore, bridges give the impression of being simple structures whose seismic response could be easily predicted. Accordingly, seismic design of bridges in Croatia have received relatively little attention in the past, maybe because we have not been exposed to a single very strong event for a long time, or because of our inert behaviour.

Seismic calculation of bridge structures in active seismic areas is a significant part of the overall calculations with the aim of proving the mechanical resistance and stability. Aseismic bridge design is of special importance because its serviceability during and after the earthquake depends on it. The territory of the Republic of Croatia is in a very active seismic area (Figure 1) so an earthquake influence on bridge structure is often relevant for the choice of bridge type structure, computation model, element dimensions, material consumption, detail solutions and for the overall bridge mechanical resistance and stability.

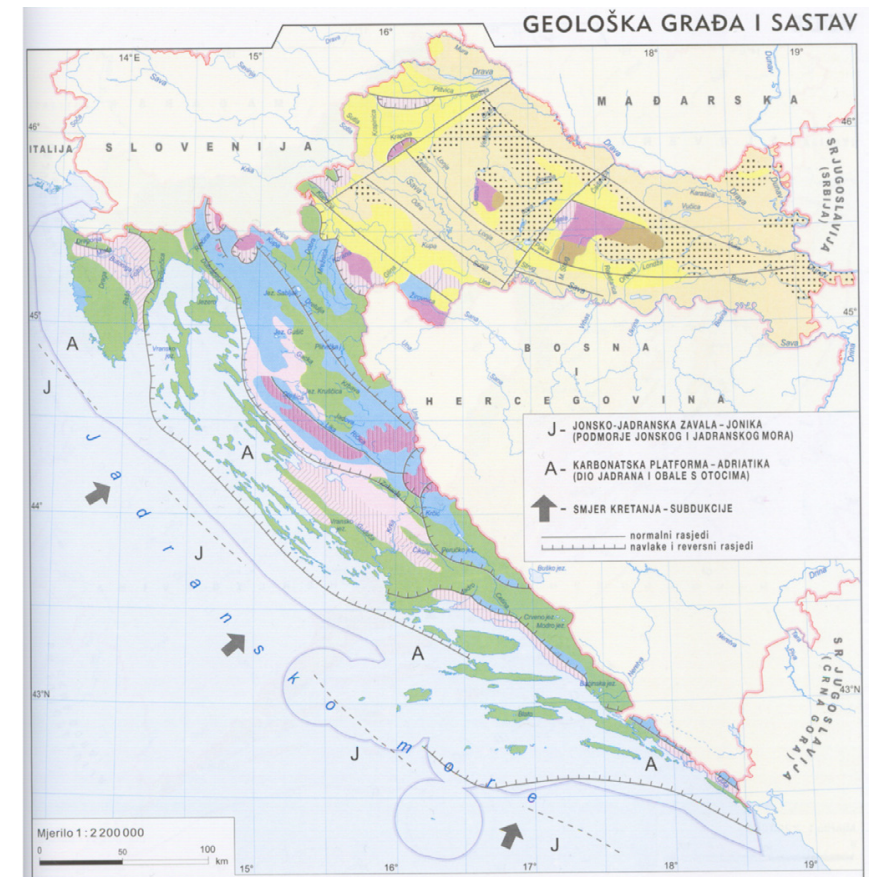

Figure 1: Geological chart of the Republic of Croatia [1].

For the last half of the century we used very simplified, out-of-date and unharmonized regulations for the seismic calculation of bridge structures like "Rules on Temporary Technical Regulations for Construction of Structures in Seismic Ares" [2] dated 1964 and "Rules on Technical Standards for Design and Calculation of Engineering Structures in Seismic Areas" [3] dated 1990. 
According to the mentioned regulations a greater reduction of inertial forces due to ground motion was permitted related to the modern European standards. Furthermore, verification of ductility was not requested although the ductility is a property which is important for dissipation of seismic energy. This approach raises a risk on bearing capacity and on serviceability of the bridge structure. Structural Eurocodes are based on the modern approach to the calculation of structures incorporating the idea of unification of the conditions for design and construction in European countries. The procedure of the seismic calculation of bridge structures according to Eurocode $8 / 2$ is the result of modern theoretic and experimental analyses and construction experiences. The results of the bridge seismic analysis according to Eurocode 8/2 are greater seismic forces and higher seismic capacity of the structure compared to the results of the previous codes.

\section{Basic principles of the bridge seismic design according to Eurocode 8/2}

The calculation philosophy of the seismic resistant bridges according to the Eurocodes is based on the demand that, during the period of bridge exploitation after the occurrence of earthquake of the predicted intensity, the bridge must not collapse (ultimate limit state) and that the damage (serviceability limit state) must not influence the traffic. Eurocode 8/2 [4] gives recommendations for the seismic calculation of bridges with a description of basic principles and rules which follow the basic demands of the seismic calculations presented in Eurocode 8/1 [4]. These rules are destined for construction girder bridges supported by abutments and vertical or nearly vertical piers, arc and frame bridges, and are not recommended for suspension bridges, highly curved bridges, bridges with significant longitudinal grade and skew bridges. Eurocode 8/2 also incorporates some basic rules and principles for constructing special bridges and seismic protection of the bridges by the use of isolation devices for the purpose of reducing the seismic response.

In designing the seismic resistant structures according to the European standards aimed to assure integrity and serviceability of the bridge structure during the earthquake with foreseen intensity, special attention should be focussed on aseismic shaping of bridges. Namely, seismic conditions, especially in the areas of higher seismic intensity, are often the decisive factor for choosing the type of structure, the load-bearing system, the connections between superstructure and substructure, dimensioning of elements and reinforcement, material consumption, detailing, etc.

In seismic active areas the bridge superstructure should be designed as a continuous deck, i.e. as a statically highly indeterminate system. That means that the superstructure should have as few expansion joints as possible. As superstructure is leaned on substructure the stiffness of abutments and piers influence the seismic forces redistribution. The dispositions of the bridges with equal pier heights is more favourable because of a more even redistribution of the seismic forces on the supporting elements, i.e. the equalization of pier dimensions and the quantity of built in reinforcement and equable distribution of 
stresses in the subsoil. Namely, the short very stiff piers as well as very high flexible piers should be avoided or expelled from the seismic forces acceptance system using flexible bearings. The first should be expelled due to the ability of accepting a greater part of the total seismic force, and the second due to the very high deformability. The ductile behaviour of bridge structure is ensured by the equalization of pier height and by making it possible to have a greater number of supporting elements to take part in the longitudinal and transverse bridge direction seismic forces acceptance with simultaneous opening of the plastic hinges in the majority of piers. The plastic hinges in piers (which are foreseen in the bottom parts) should be ensured according to the foreseen pier deformation by adequate reinforcement taking the damage into consideration which must not affect the traffic on the bridge. The eventuality of damage occurrence should be foreseen in easily accessible places due to the easy detection and repair. The opening of the plastic hinges in the bridge superstructure is not allowed. The plastic hinges will not open in the piers flexibly connected to the bridge superstructure and in the piers with the smaller stiffness compared with the other bridge piers. The bridge foundations should stay undamaged upon seismic actions.

The behaviour of the bridge during an earthquake can be designed by the adequate disposition of the elastomeric bearings upon which the bridge superstructure is leaned on abutments and piers. The flexibility of the elastomeric bearings (increasing its height) causes the prolongation of the fundamental period of the bridge and the reduction of the seismic force. At the same time, displacements of the structure are increased which causes a need for placing bigger and more expensive expansion joints or increases the number of bridge dilatations. To reduce the displacements of the structure it is possible to direct the dissipation of the seismic energy to the abutments and piers with seismic dampers. Furthermore, for leaning the superstructure on the substructure over the movable bearings it is necessary to assure the satisfactory width of the superstructure overlapping in order to prevent the falling of the bridge superstructure during extreme movements. In that case, the structure should be additionally assured by designing seismic boundary stone on the piers, i.e. by appropriate design and reinforcement of the breast abutment wall. The combination of all the aforementioned points would be the most effective in high seismic areas.

\section{Design of seismic isolated bridges}

\subsection{Basic principle of seismic isolation}

Seismic isolation is used as a common way to reduce the seismic action to the structure and to prevent the structural damage. Two systems can be used: isolators and dampers. Isolators are flexible devices which reduce the stiffness of the structure and the period of the structure becomes longer. Dampers reduce seismic load according to the principle of energy dissipation. Figure 2 shows the basic principle of seismic isolation [5]. 


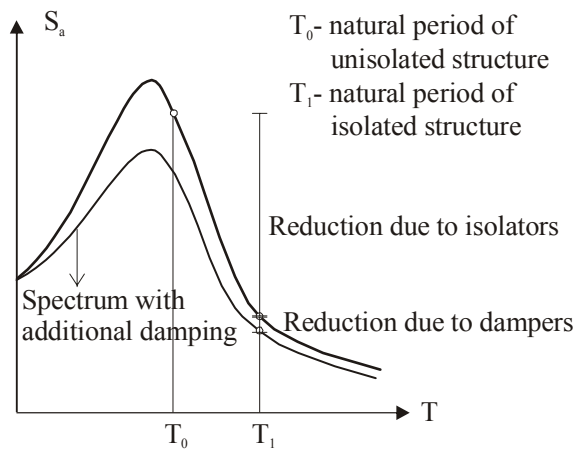

Figure 2: Basic principle of seismic isolation [5].

Elastomeric bearings are frequently used as isolators to lengthen a natural period of bridges, especially viaducts. They are situated between the superstructure and columns. They have a great bearing capacity and stiffness in the vertical direction and less shear stiffness in the horizontal direction which implies the reduction of the total structural stiffness in the longitudinal and transversal direction, as well as reduction of the seismic load. An earthquake causes large horizontal displacements and deformation of the bearings. Therefore, the choice of the bearings has significant influence on the obtained results.

\subsection{Methods of analysis of seismically isolated viaducts}

Several methods can be used for the analysis of seismically isolated viaducts. The type of analysis can be linear or non-linear, while the dynamic model is single-degree of freedom or multi-degree of freedom. Eurocode 8/2 proposes the following methods for analysis of bridges: fundamental mode method, response spectrum method, alternative linear methods (power spectrum analysis, time series analysis) and non-linear time domain analysis. Some examples of the engineering modelling of seismically isolated viaducts with the discussion of the influencing parameters can be found in Ref. [6].

The corresponding dynamic equation in the analysis of seismic isolated viaducts includes mass, damping and stiffness matrix, time, acceleration, velocity, displacement and load vectors. The change of the damping matrix, the stiffness matrix and the load vector over time depends on the applied accelerogram. The change of stiffness matrix in isolated viaducts depends, not only on accelerogram, but also on the changing of elastomeric bearings stiffness. This change depends on the force in elastomeric bearings. The damping matrix in isolation systems also additionally changes due to the velocity in the bearings. The use of non-linear models in seismic analysis of isolated bridges is necessary to obtain relevant results especially for complex bridges with large spans, the stiffness changes, dilatations, etc.

In spite of that, European codes have a tendency toward simplification of the analysis procedure. A linear method of analysis is more favourably received by 
designers in relation to a non-linear dynamic analysis. The fundamental mode method and response spectrum method are preferred in engineering practice.

The fundamental mode method gives equivalent static seismic forces which are derived from the inertia forces corresponding to the fundamental natural period of the structure in the direction under consideration. The method includes simplifications regarding the shape of the first mode and the estimation of the fundamental period. The method can be applied in all cases in which the dynamic behaviour of the structure can be sufficiently approximated by a single dynamic degree of freedom model.

The response spectrum method can provide an acceptable approximation if the appropriate approximation of the elastomeric bearings is applied. However, the typical behaviour of elastomeric bearings is elastoplastic [5] so it is difficult to model their characteristics by a linear model. In addition, the modulus of elasticity is different in the vertical and horizontal directions, which should be considered in numerical modelling. The elasticity modulus can be expressed according to the literature $[5,7,8]$.

The stiffness of bearings is a function of the shear modulus G. According to Eurocode $8 / 2$ the shear modulus for normal laminated bearings is $G=1.2 \mathrm{~N} / \mathrm{mm}^{2}$ for $\varepsilon_{\mathrm{S}} \leq 1.2$ and $\mathrm{G}=1.6 \mathrm{~N} / \mathrm{mm}^{2}$ for $\varepsilon_{\mathrm{S}}=2.0$ where $\varepsilon_{\mathrm{S}}$ is the shear strain due to the total seismic displacement. The choice of shear modulus is not simple because whole seismic computation of the structure is performed for presumed magnitude. The verification of the shear modulus is performed during dimensioning of the bearings when the shear strains are computed. The difference in horizontal displacements of the structures for $G=1.2 \mathrm{~N} / \mathrm{mm}^{2}$ or $\mathrm{G}=1.6 \mathrm{~N} / \mathrm{mm}^{2}$ can be $20 \%$.

In the application of the response spectrum method on isolated bridges it is necessary to apply several approximations in modelling of elastomeric bearings which can influence the results.

\section{Numerical examples}

Comparative analysis of the results obtained by the fundamental mode method and the response spectrum method for several viaducts at the Adriatic highway [9-12] will be presented.

Viaducts consist of superstructure supported by abutments and piers. The reduction of the seismic action is performed with elastomeric bearings between superstructure and substructure. The behaviour factor of the structure is $q=1.0$ and subsoil class is A. The elasticity modulus of the concrete is $31500 \mathrm{MPa}$. The cross sections of all piers are equal. The cross sectional area is $A=2.64 \mathrm{~m}^{2}$ and the moments of inertia are $\mathrm{I}_{x}=2.8872 \mathrm{~m}^{4}$ and $\mathrm{I}_{\mathrm{y}}=1.4512 \mathrm{~m}^{4}$. The weight of the structure consists of the deck weight, the weights of piers and $20 \%$ of variable load at the viaduct. The mass of piers is $6.73 \mathrm{kNs}^{2} / \mathrm{m}$. The total effective mass is less than or close to $1 / 5$ of the mass of the deck. The theoretical eccentricity between the centre of stiffness of the supporting elements and the centre of mass of the deck does not exceed $5 \%$ of the length of the deck. The analyzed viaducts 
are on the limit-line between the application of the fundamental mode method and the response spectrum method according to their characteristics.

Longitudinal sections of the viaducts with design acceleration, characteristics of elastomeric bearings and the heights of piers are shown in Figure 3.

Heights of piers:

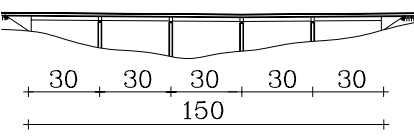

a) Viaduct $1, \mathrm{a}_{\mathrm{g}}=0.1 \mathrm{~g}$

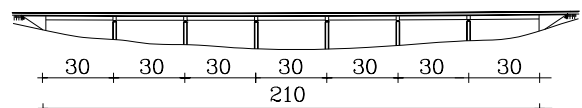

b) Viaduct 2, $\mathrm{a}_{\mathrm{g}}=0.1 \mathrm{~g}$

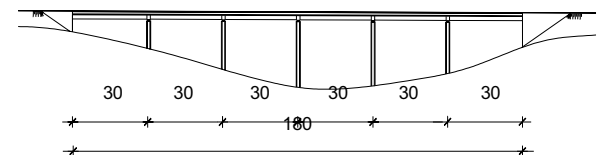

c) Viaduct 3, $\mathrm{a}_{\mathrm{g}}=0.1 \mathrm{~g}$

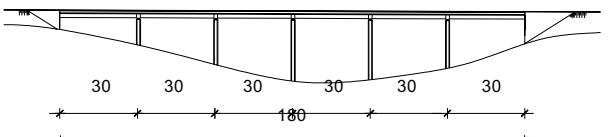

d) Viaduct $4, \mathrm{a}_{\mathrm{g}}=0.1 \mathrm{~g}$ $\mathrm{h}_{1}=5.40 \mathrm{~m}, \mathrm{~h}_{2}=13.16 \mathrm{~m}$, $\mathrm{h}_{3}=20.40 \mathrm{~m}, \mathrm{~h}_{4}=10.09 \mathrm{~m}$

Elastomeric bearings:

$\mathrm{U}_{1}, \mathrm{U}_{2}: 2 \mathrm{x} \phi 750 / 130 \mathrm{~mm}$

$\mathrm{S}_{1}, \mathrm{~S}_{4}: 2 \times \phi 750 / 90 \mathrm{~mm}$

$$
\left(\mathrm{t}_{\mathrm{t}}=95 \mathrm{~mm}\right)
$$

$\left(\mathrm{t}_{\mathrm{t}}=65 \mathrm{~mm}\right)$

$\mathrm{S}_{2}, \mathrm{~S}_{3} 2 \times \phi 750 / 50 \mathrm{~mm}\left(\mathrm{t}_{\mathrm{t}}=35 \mathrm{~mm}\right)$

Heights of piers:

$\mathrm{h}_{1}=6.29 \mathrm{~m}, \mathrm{~h}_{2}=7.98 \mathrm{~m}$,

$\mathrm{h}_{3}=9.74 \mathrm{~m}, \mathrm{~h}_{4}=11.06 \mathrm{~m}$,

$\mathrm{h}_{5}=9.45 \mathrm{~m}, \mathrm{~h}_{6}=7.42 \mathrm{~m}$

Elastomeric bearings:

$\mathrm{U}_{1}, \mathrm{U}_{2}: 2 \mathrm{x} \phi 750 / 150 \mathrm{~mm}$

$$
\left(\mathrm{t}_{\mathrm{t}}=110 \mathrm{~mm}\right)
$$

$\mathrm{S}_{1}, \mathrm{~S}_{6}: 2 \mathrm{x} \phi 750 / 110 \mathrm{~mm}$

$\mathrm{S}_{2}, \mathrm{~S}_{5}: 2 \times \phi 750 / 90 \mathrm{~mm}$

$$
\left(t_{t}=75 \mathrm{~mm}\right)
$$

$$
\left(\mathrm{t}_{\mathrm{t}}=60 \mathrm{~mm}\right)
$$

$\mathrm{S}_{3}, \mathrm{~S}_{4}: 2 \times 150 / 70 \mathrm{~mm}\left(\mathrm{t}_{\mathrm{t}}=45 \mathrm{~mm}\right)$

Heights of piers:

$\mathrm{h}_{1}=5.63 \mathrm{~m}, \mathrm{~h}_{2}=7.82 \mathrm{~m}$,

$\mathrm{h}_{3}=9.58 \mathrm{~m}, \mathrm{~h}_{4}=10.40 \mathrm{~m}$,

$\mathrm{h}_{5}=8.79 \mathrm{~m}$

Elastomeric bearings:

$\mathrm{U}_{1}, \mathrm{U}_{2}: 2 \mathrm{x} \phi 750 / 150 \mathrm{~mm}$

$\mathrm{S}_{1}, \mathrm{~S}_{5}: 2 \mathrm{x} \phi 750 / 110 \mathrm{~mm}$

$$
\left(\mathrm{t}_{\mathrm{t}}=110 \mathrm{~mm}\right)
$$

$\mathrm{S}_{2}, \mathrm{~S}_{3}: 2 \times \phi 750 / 90 \mathrm{~mm}$

$$
\left(t_{t}=75 \mathrm{~mm}\right)
$$

$$
\begin{array}{ll}
\mathrm{S}_{3}: 2 \times \phi 750 / 70 \mathrm{~mm} & \left(\mathrm{t}_{\mathrm{t}}=60 \mathrm{~mm}\right) \\
\left(\mathrm{t}_{\mathrm{t}}=45 \mathrm{~mm}\right)
\end{array}
$$

Heights of piers:

$\mathrm{h}_{1}=7.79 \mathrm{~m}, \mathrm{~h}_{2}=12.94 \mathrm{~m}$, $\mathrm{h}_{3}=13.6 \mathrm{~m}, \mathrm{~h}_{4}=13.25 \mathrm{~m}$, $\mathrm{h}_{5}=8.40 \mathrm{~m}$

Elastomeric bearings:

$\mathrm{U}_{1}, \mathrm{U}_{2}: 2 \mathrm{x} \phi 750 / 150 \mathrm{~mm}$

$$
\left(\mathrm{t}_{\mathrm{t}}=110 \mathrm{~mm}\right)
$$

$\mathrm{S}_{1}, \mathrm{~S}_{5}: 2 \times \phi 750 / 110 \mathrm{~mm}$

$\mathrm{S}_{2}, \mathrm{~S}_{3}: 2 \times \phi 750 / 90 \mathrm{~mm}$

$$
\left(t_{t}=80 \mathrm{~mm}\right)
$$

$\mathrm{S}_{2}: 2 \times \phi 750 / 70 \mathrm{~mm} \quad \begin{aligned} & \left(\mathrm{t}_{\mathrm{l}}=65 \mathrm{~mm}\right) \\ & \left(\mathrm{t}_{\mathrm{t}}=50 \mathrm{~mm}\right)\end{aligned}$

Figure 3: $\quad$ Main characteristics of the analyzed viaducts. 


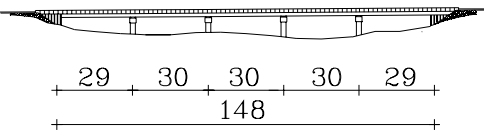

e) Viaduct 5, $\mathrm{a}_{\mathrm{g}}=0.2 \mathrm{~g}$

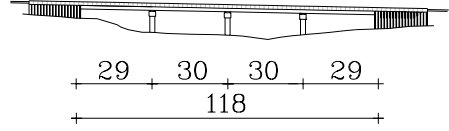

f) Viaduct 6, $\mathrm{a}_{\mathrm{g}}=0.29 \mathrm{~g}$

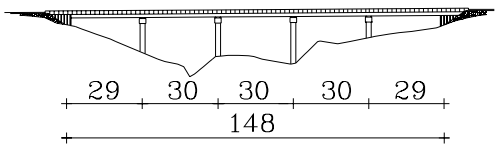

g) Viaduct 7, $\mathrm{a}_{\mathrm{g}}=0.29 \mathrm{~g}$
Heights of piers:

$\mathrm{h}_{1}=8.31 \mathrm{~m}, \mathrm{~h}_{2}=10.96 \mathrm{~m}$, $\mathrm{h}_{3}=10.07 \mathrm{~m}, \mathrm{~h}_{4}=12.69 \mathrm{~m}$

Elastomeric bearings:

$\mathrm{U}_{1}, \mathrm{U}_{2}: 5 \times \phi 500 / 159 \mathrm{~mm}$

$\mathrm{S}_{1}, \mathrm{~S}_{4}: 10 \mathrm{x} \phi 500 / 144 \mathrm{~mm}$

$$
\left(\mathrm{t}_{\mathrm{t}}=115 \mathrm{~mm}\right)
$$

$$
\left(t_{t}=104 \mathrm{~mm}\right)
$$

$\mathrm{S}_{2}, \mathrm{~S}_{3}: 10 \times \phi 500 / 99 \mathrm{~mm}$

$$
\left(\mathrm{t}_{\mathrm{t}}=71 \mathrm{~mm}\right)
$$

Heights of piers:

$\mathrm{h}_{1}=13.28 \mathrm{~m}, \mathrm{~h}_{2}=16.77 \mathrm{~m}$,

$\mathrm{h}_{3}=14.48 \mathrm{~m}$

Elastomeric bearings:

$\mathrm{U}_{1}, \mathrm{U}_{2}: 5 \mathrm{x} \phi 500 / 129 \mathrm{~mm}$

$\mathrm{S}_{1}, \mathrm{~S}_{3}: 10 \mathrm{x} \phi 500 / 114 \mathrm{~mm}$

$$
\left(\mathrm{t}_{\mathrm{t}}=88 \mathrm{~mm}\right)
$$

$\mathrm{S}_{2}: 10 \mathrm{x} \phi 500 / 84 \mathrm{~mm}\left(\mathrm{t}_{1}=60 \mathrm{~mm}\right)$

Heights of piers:

$\mathrm{h}_{1}=19.11 \mathrm{~m}, \mathrm{~h}_{2}=21.23 \mathrm{~m}$,

$\mathrm{h}_{3}=20.85 \mathrm{~m}, \mathrm{~h}_{4}=10.44 \mathrm{~m}$

Elastomeric bearings:

$\mathrm{U}_{1}, \mathrm{U}_{2}: 5 \times 1500 / 159 \mathrm{~mm}$

$$
\left(t_{t}=110 \mathrm{~mm}\right)
$$

$\mathrm{S}_{1}, \mathrm{~S}_{4}: 10 \mathrm{x} \phi 500 / 114 \mathrm{~mm}$

$\mathrm{S}_{2}, \mathrm{~S}_{3}: 10 \mathrm{x} \phi 500 / 99 \mathrm{~mm}$ $\left(\mathrm{t}_{\mathrm{t}}=77 \mathrm{~mm}\right)$

$\left(\mathrm{t}_{\mathrm{t}}=71 \mathrm{~mm}\right)$

Figure 3: (continued).

Table 1 shows the results in the longitudinal direction obtained by the fundamental mode method with the rigid deck model approach and response spectrum method. The fundamental mode is firstly computed for a rigid structure without elastomeric bearings, $\mathrm{T}_{\mathrm{S}}$. After that, the period based on the stiffness of elastomeric bearings $\mathrm{T}_{\mathrm{EB}}$ is computed and finally the fundamental period of isolated viaducts is obtained with the expression $\mathrm{T}_{\mathrm{FP}}=\sqrt{\mathrm{T}_{\mathrm{S}}^{2}+\mathrm{T}_{\mathrm{EB}}{ }^{2}}$. For the computed period an ordinate of the design spectrum, $\mathrm{R}(\mathrm{T})=\mathrm{a}_{\mathrm{g}} \mathrm{S \eta} \beta_{0}\left(\mathrm{~T}_{\mathrm{C}} / \mathrm{T}\right)^{\mathrm{k}_{1}}$, and the equivalent seismic force, $\mathrm{F}_{\mathrm{FP}}(\mathrm{T})=\mathrm{R}(\mathrm{T}) \cdot \mathrm{M}$, are calculated. The calculation of the stiffness of structure is based on the stiffness of piers $\mathrm{K}_{\mathrm{s}}=\Sigma \mathrm{k}_{\mathrm{i}}$ $=3 \mathrm{EI} \Sigma \mathrm{L} / \mathrm{h}_{\mathrm{i}}^{3}$ where $\mathrm{E}$ is the modulus of elasticity, $\mathrm{I}$ is the moment of inertia, $\mathrm{L}$ is the span of the viaduct and $h_{i}$ is the height of each pier. The horizontal stiffness of elastomeric bearings is given by the expression $k_{h}=G A / t_{t}$, where $G$ is the shear modulus, $\mathrm{A}$ is the area of the elastomers and $t_{t}=\Sigma t_{i}$ is the total thickness of the elastomer layers. 
The response spectrum method gives the first period $T_{R S}$ and the total seismic force $\mathrm{F}_{\mathrm{RS}}$.

Analysis of the viaducts by the response spectrum method shows that the first mode activates a considerable part of the total mass of the viaduct. The first mode activates more than $90 \%$ of the total mass in all viaducts, while the first transversal mode activates more than $85 \%$ of the mass. The influence of the other transversal modes on the total seismic transversal force, as well as horizontal forces in elastomeric bearings and piers is negligible. The difference of the total seismic horizontal force in the longitudinal direction obtained by the response spectrum method and fundamental mode method for analysed viaducts is less than $11 \%$. Similar results are obtained in the transversal direction. If we take into consideration that the simulation of the elastoplastic behaviour of elastomeric bearings in the linear response spectrum method is not possible, the obtained differences in practical engineering can be tolerated.

Table 1: Comparative analysis by fundamental mode method (FP) and response spectrum method (RS).

\begin{tabular}{|c|c|c|c|c|c|c|}
\hline Viaduct & $\mathrm{T}_{\mathrm{S}}(\mathrm{s})$ & $\mathrm{T}_{\mathrm{EB}}(\mathrm{s})$ & $\mathrm{T}_{\mathrm{FP}}(\mathrm{s})$ & $\mathrm{F}_{\mathrm{FP}}(\mathrm{kN})$ & $\mathrm{T}_{\mathrm{RS}}(\mathrm{s})$ & $\mathrm{F}_{\mathrm{RS}}(\mathrm{kN})$ \\
\hline 1 & 0.380 & 1.170 & 1.226 & 3080 & 1.330 & 2722 \\
\hline 2 & 0.394 & 1.370 & 1.426 & 6497 & 1.340 & 7132 \\
\hline 3 & 0.368 & 1.340 & 1.390 & 5625 & 1.350 & 6064 \\
\hline 4 & 0.553 & 1.464 & 1.565 & 5342 & 1.430 & 6076 \\
\hline 5 & 0.548 & 1.113 & 1.241 & 9560 & 1.140 & 8638 \\
\hline 6 & 0.909 & 0.929 & 1.300 & 9011 & 1.127 & 10320 \\
\hline 7 & 1.010 & 1.078 & 1.477 & 13055 & 1.437 & 13710 \\
\hline
\end{tabular}

\section{Conclusion}

As the national territory of the Republic of Croatia is in a very active seismic area, earthquake influence on bridge structure is often relevant for the choice of span number, the type of bridge superstructure, piers disposition and their height and stiffness, the connection between piers and superstructure or piers and foundations, dimensioning of elements and reinforcement, detail solutions, material consumption, etc.

So, in this paper we present comparative analysis of the results obtained by two different methods proposed in Eurocode 8/2, i.e. the fundamental mode method and the response spectrum method for several seismic isolated viaducts at the Adriatic highway.

The performed analyses show: (i) obtained seismic forces by these two methods are almost the same; the difference is within $10 \%$; (ii) the fundamental mode method gives the results of sufficient accuracy although the viaducts are at the limit which Eurocode $8 / 2$ recommend for use of the fundamental mode method. 


\section{Acknowledgements}

The partial financial support, provided by the Ministry of Science, Education and Sports of the Republic of Croatia under the projects Numerical and Experimental Models of Engineering Structures, Grant No. 0083061, Numerical and Experimental Investigations of Engineering Structures Behaviour, Grant No. 083-0831541-1547 and Non-linear Dynamic Analysis of Three-dimensional Reinforced Concrete Structures, Grant No. 083-0831541-1532, is gratefully acknowledged.

\section{References}

[1] The Great Atlas of Croatia, Mozaik knjiga, Zagreb, p. 399, 2002, (in Croatian)

[2] Rules on Temporary Technical Regulations for Construction of Structures in Seismic Ares. Official Bulletin 39/64, 1964. (in Croatian)

[3] Rules on Technical Standards for Design and Calculation of Engineering Structures in Seismic Areas. 1990. (in Croatian)

[4] Eurocode 8. Design Provisions for Earthquake Resistance of Structures. European Committee for Standardization, ENV 1998-1 \& ENV 1998-2, Brussels, 1994.

[5] Naeim, F. \& Kelly, J.M., Design of Seismic Isolated Structures, John Wiley \& Sons, 2002.

[6] Isaković, T. \& Fischinger, M., Engineering modelling of seismically isolated viaducts. Engineering Modelling, 15(1-4), pp. 93-98, 2002.

[7] Nikolić, Ž. \& Herak Marović, V., Aspects of Seismic Bridge Design, Proc. of the Int. Conf. on Bridges, ed. J. Radić, Structural Engineering Conferences and Croatia Society of Structural Engineers: Zagreb, pp. 471478, 2006.

[8] Šimunić, Ž., Radić, J., Mekjavić, I. \& Pavlović, B., Girder bridge durability analysis based on dynamic and static indicators. Gradevinar, 53(2), pp. 61-81, 2001. (in Croatian)

[9] Radnić. J., Herak-Marović, V., Nikolić, Ž., et al., Some structures on the highway Zagreb-Split-Dubrovnik from Zadar to Bisko, Proc. of the Congress of HSGI, ed. V. Simović, HSGI: Zagreb, pp. 517-531, 2004. (in Croatian)

[10] Main Designs of Viaducts at the Adriatic Highway, Section Zadar 2Benkovac, IGH PC Split, Split, 2001. (in Croatian)

[11] Main Designs of Viaducts at the Adriatic Highway, Section VrpoljePrgomet, IGH PC Split, Split, 2002. (in Croatian)

[12] Main Designs of Viaducts at the Adriatic Highway, Section DugopoljeBisko, IGH PC Split, Split, 2004. (in Croatian) 